\title{
INFLUÊNCIA DO SISTEMA DE CORTE BASAL DE MINIESTACAS NA PROPAGAÇÃO CLONAL DE HÍBRIDO DE Eucalyptus urophylla X Eucalyptus globulus subsp. maidenii ${ }^{1}$
}

\author{
Alan Ferreira Batista ${ }^{2}$, Glêison Augusto dos Santos ${ }^{3}$, Luciana Duque Silva ${ }^{4}$, Franco Freitas Quevedo ${ }^{5}$ \\ Teotônio Francisco de Assis ${ }^{6}$
}

\begin{abstract}
RESUMO - A técnica de miniestaquia permitiu o estabelecimento de florestas clonais em larga escala. Porém, pouco se avançou no seu manejo em viveiro para genótipos recalcitrantes. Assim, esse estudo teve como objetivo avaliar a influência do sistema de cortes na base de miniestacas na produção de mudas de um clone híbrido de Eucalyptus urophylla x Eucalyptus globulus subsp. maidenii. Desta forma, foram realizadas três avaliações: 1) sobrevivência aos 30 dias em casa de vegetação; 2) enraizamento aos 45 dias em casa de sombra; e 3) aproveitamento final aos 60 dias na área de rustificação. O índice de enraizamento foi determinado com base no percentual de sobrevivência. O delineamento experimental utilizado foi em blocos casualizados constituído de três tratamentos: 1) miniestacas com corte na base perpendicular (testemunha); 2) miniestacas com corte na base em bisel (corte diagonal) e 3) miniestacas cortadas perpendicularmente, com três incisões longitudinais na base. Foram avaliadas quatro blocos de 228 plantas por bloco. Os resultados de enraizamento foram superiores a 80\% nos melhores tratamentos e indicam que a propagação do clone via miniestaquia é viável, não apresentando comportamento recalcitrante. Os sistemas de corte basal das miniestaca em bisel e as incisões não favoreceram a formação de raízes.
\end{abstract}

Palavras-chave: Viveiro; Enraizamento; Incisões.

\section{INFLUENCE OF BASAL CUTTING SYSTEM OF MINICUTINGS IN CLONAL PROPAGATION OF Eucalyptus urophylla $X$ Eucalyptus globulus subsp. maidenii hybrid $^{1}$}

\begin{abstract}
Mini-cutting technique has allowed establishing large scale clonal forests. However small progress has been observed in nursery management practices for recalcitrant genotypes. The present work aimed to evaluate the influence of different base cut systems in mini-cuttings for seedlings production of a hybrid clone of Eucalyptus urophylla $x$ Eucalyptus globulus subsp. maidenii. Three evaluations were performed: 1) survival in the greenhouse at the $30^{\text {th }}$ day; 2) number of rooted seedlings in the shade house at the $45^{\text {th }}$ day; and 3 ) viable seedlings in the hardening area at the $60^{\text {th }}$ day. Rooting evaluation was based on survival rate. The experimental design was in randomized blocks with four replications and three treatments: 1) perpendicular cut at the base of mini-cuttings (control); 2) bevel cut at the base of mini-cuttings (diagonal cut); 3) perpendicular cut at the base of mini-cuttings with three longitudinal incisions in the base. Four blocks were assessed, each block was composed by 228 plants. The results of rooting were over $80 \%$ in the best treatments, indicating that the clone propagation is feasible using mini-cutting technique, and it does not show a recalcitrant behavior. The basal cut system in bevel and in longitudinal incisions did not favor rooting.
\end{abstract}

Keywords: Nursery; Rooting; Incisions.

\footnotetext{
${ }^{1}$ Recebido em 25.02.2014 aceito para publicação em 04.07.2014.

${ }^{2}$ Assuntos Florestais, Indústria Brasileira de Árvores, IBA, Brasil. E-mail: <alan.batista@iba.org>e < alan.batista@usp.br>.

${ }^{3}$ Centro de Produção Tecnológica, CMPC Celulose Riograndense, Brasil. E-mail: <gaugusto@cmpcrs.com.br>.

${ }^{4}$ Escola Superior de Agricultura "Luiz de Queiroz" - ESALQ/USP, Universidade de São Paulo, Brasil. E-mail: <lucianaduques@usp.br> .

${ }^{5}$ Centro de Produção Tecnológica, CMPC Celulose Riograndense, Brasil. E-mail: <ffquevedo@cmpcrs.com.br>.

${ }^{6}$ Assistech Serviços Técnicos Florestais Ltda., Brasil. E-mail: <assisteo@terra.com.br>.
} 


\section{INTRODUÇÃO}

Na década de 1990, foi implementada a propagação vegetativa por miniestaquia no gênero Eucalyptus (XAVIER; COMÉRIO, 1996), que permitiu a maximização dos plantios clonais no Brasil em escala comercial e elevou consideravelmente os níveis de enraizamento de diferentes espécies e clones. Apesar dos avanços da técnica de miniestacas, clones recalcitrantes ao enraizamento via propagação vegetativa, em particular àqueles da espécie Eucalyptus globulus, ainda apresentam barreiras ao estabelecimento de florestas clonais comerciais, tanto em função de baixos índices de enraizamento quanto da dificuldade de adaptação ao ambiente tropical.

Somente cerca de 1-2\% das árvores-elite de Eucalyptus globulus selecionadas apresentam enraizamento médio de 60\%. Em razão desses baixos índices de enraizamento dessa espécie, a tendência é a valorização dos cruzamentos controlados para reproduzir comercialmente, por vias seminais, pares de cruzamentos superiores (ALFENAS et al., 2009).

No Brasil, a hibridação com espécies tropicais, principalmente Eucalyptus urophylla, é uma técnica que vem sendo adotada para melhorar a adaptação das espécies às condições ambientais e, também, facilitar a propagação vegetativa de espécies recalcitrantes ao enraizamento (ASSIS; MAFIA, 2007).

A formação de raízes em miniestacas é um processo fisiológico complexo, associado ao desenvolvimento de células totipotentes que originam meristemas que promovem o enraizamento adventício (ALFENAS et al., 2009). Alguns reguladores de crescimento, como ácido abscísico, auxinas, citocininas, giberilinas e compostos fenólicos, exercem influência na formação do enraizamento adventício (HARTMANN et al., 2002).

Algumas espécies de Eucalyptus, em especial o Eucalyptus globulus, possuem baixa predisposição ao enraizamento. Assim como em outras espécies madeireiras de alta densidade, a possível explicação para a deficiência dessas espécies na emissão de raízes são as barreiras físicas provocadas pela presença de anéis esclerenquimáticos na base da miniestaca (ALFENAS et al., 2009).

Apesar de miniestacas possuírem características de plantas herbáceas, é possível que apresentem algum grau de lignificação, dependendo do período de coleta, condição fisiológica da minicepa e idade da miniestaca. Fachinello et al. (2005) relataram que alto grau de lignificação de estacas pode ser prejudicial ao processo de enraizamento, em parte devido à formação de barreiras anatômicas à emissão dos primórdios radiculares.

Incisões na base das estacas permitem que haja o rompimento de barreira física exercida pelos anéis de esclerênquima, além do aumento da taxa respiratória, acúmulo de carboidratos e auxinas na área lesionada, o que pode favorecer a emissão de raízes, principalmente em estacas que apresentem maior grau de lignificação (FACHINELLO et al., 1995; HARTMANN et al., 2002).

Estudos que investigaram a influência de incisões basais e auxinas exógenas no enraizamento de estacas lenhosas, semilenhosas e herbáceas relatam resultados divergentes, mostrando interações ausentes ou positivas entre o corte na base de estacas e enraizamento (CAMOLESI et al., 2007; ALMEIDA et al., 2008; TREVISAN et al., 2008; BASTOS et al., 2009).

Trabalhos que investigaram a influência de incisões basais ou cortes em bisel na propagação clonal de Eucalyptus por miniestaquia não foram encontrados na literatura. Diante do exposto, este estudo teve como objetivo avaliar a influência do tipo de corte na base de miniestacas no enraizamento e produção de mudas de um clone híbrido de Eucalyptus urophylla x Eucalyptus globulus subsp. maidenii.

\section{MATERIAL E MÉTODOS}

\section{1. Área de estudo}

Este estudo foi realizado no Município de Barra do Ribeiro, RS, na latitude $30^{\circ} 17^{\prime \prime}$ Sul, longitude $51^{\circ} 18^{\prime \prime}$ Oeste e altitude de $12 \mathrm{~m}$. De acordo com a classificação de Köppen, o clima predominante na região é do tipo Cfa, subtropical úmido e a precipitação média anual é de aproximadamente $1.400 \mathrm{~mm}$. A temperatura da média do mês mais quente não ultrapassa $25^{\circ} \mathrm{C}$ e a do mês mais frio, $14^{\circ} \mathrm{C}$, com ocorrência de geadas leves.

\subsection{Manejo de minijardim clonal}

As minicepas nas quais foram coletadas as miniestacas utilizadas na realização do estudo foram plantadas em leitos de areia fertirrigadas em sistema de gotejamento automatizado, sob abrigo de teto retrátil. O sistema de fertirrigação foi acionado de três a quatro vezes ao dia, dependendo das condições climáticas 
fornecendo $5 \mathrm{~L} \mathrm{~m}^{-2}$ por dia de solução e condutividade elétrica (Ec) mantida em 1,8 $\mathrm{mS} \mathrm{m}^{-2}$. A solução nutritiva foi composta por nitrato de cálcio $\left(367,5 \mathrm{mg} \mathrm{L}^{-1}\right)$; fosfato de monoamônio (60,2 $\mathrm{mg} \mathrm{L}^{-1}$ ); cloreto de potássio (239,4 $\mathrm{mg} \mathrm{L}^{-1}$ ); sulfato de magnésio (113,6 $\mathrm{mg} \mathrm{L}^{-1}$ ); quelato de ferro (5,0 $\left.\mathrm{mg} \mathrm{L}^{-1}\right)$; boro orgânico $\left(0,5 \mathrm{mg} \mathrm{L}^{-1}\right)$; sulfato de manganês $\left(1,8 \mathrm{mg} \mathrm{L}^{-1}\right)$; sulfato de cobre $(0,15 \mathrm{mg}$ $\left.\mathrm{L}^{-1}\right)$; e sulfato de zinco $\left(0,25 \mathrm{mg} \mathrm{L}^{-1}\right)$. O intervalo entre a coleta e o plantio das miniestacas foi de aproximadamente 20 min até que elas fossem levadas para a casa de vegetação. Plantadas em tubetes de polipropileno com volume de $55 \mathrm{~cm}^{3}$, em substrato composto por $20 \%$ de vermiculita e $80 \%$ de turfa canadense e adubação de base (PG mix ${ }^{\mathrm{TM}}$; super simples (fosfato); e osmocote (NPK; 19:06:10), respectivamente, nas dosagens de 2,0 kg; 2,0 kg; e 1,5 $\mathrm{kg} \mathrm{m}^{-3}$ de substrato). O plantio das miniestacas foi realizado no galpão de estaqueamento. As casas de vegetação possuem sistema de irrigação por nebulização realizada por bicos do tipo fogger com vazão de 7,5 L h'-1, com controle automatizado de umidade e lâmina de água, variando a intensidade de acordo com as condições climáticas. Na fase de rustificação, o sistema de irrigação é do tipo por aspersão com vazão de $120 \mathrm{~L} \mathrm{~h}^{-1}$, assim como em todas as outras etapas de irrigação, a intensidade variava de acordo com as condições climáticas.

\subsection{Experimento}

O experimento foi instalado e conduzido no período de maio a junho de 2011. Como material de suporte foram utilizadas bandejas com capacidade de 228 mudas, o delineamento experimental utilizado foi em blocos casualizados, constituído de um clone de Eucalyptus urophylla x Eucalyptus globulus subsp. maidenii, com três tratamentos, representados por tipos de cortes na base das miniestacas, com quatro repetições de 228 plantas por tratamento, totalizando 2.736 plantas analisadas.

Os cortes na base das miniestacas foram (Figura 1): T1 - miniestacas com corte na base perpendicular (testemunha); T2 - miniestacas com corte na base em bisel (corte diagonal); e T3 - miniestacas cortadas perpendicularmente, com três incisões na base de 1 cm e profundidade o suficiente para romper a casca da haste da miniestaca.

Para o tratamento que incluiu incisão basal foi desenvolvido um sistema (Figura 2) contendo três lâminas de bisturi, equidistantes, coladas em três microtubos de PVC flexível de $5 \mathrm{~mm}$ de diâmetro, de forma que
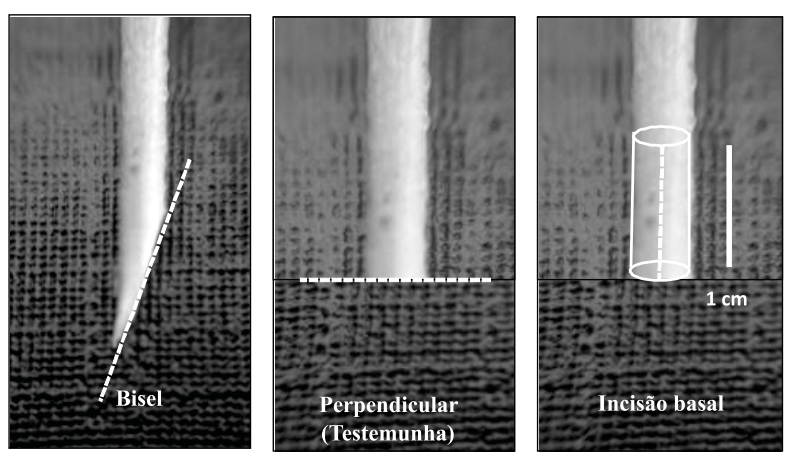

Figura 1 - Detalhe dos cortes realizados na base das miniestacas de Eucalyptus urophylla x Eucalyptus globulus subsp. maidenii.

Figure 1-Details of the cuts in the base of Eucalyptus urophylla $x$ Eucalyptus globulus subsp. Maidenii mini-cuttings.

a distância entre as lâminas se adaptassem ao diâmetro da miniestaca e rompesse apenas a casca de sua haste até a altura de $1 \mathrm{~cm}$.

\subsection{Coleta de dados}

As avaliações foram realizadas em três fases da produção de mudas: 1) sobrevivência aos 30 dias em casa de vegetação; 2) enraizamento aos 45 dias em

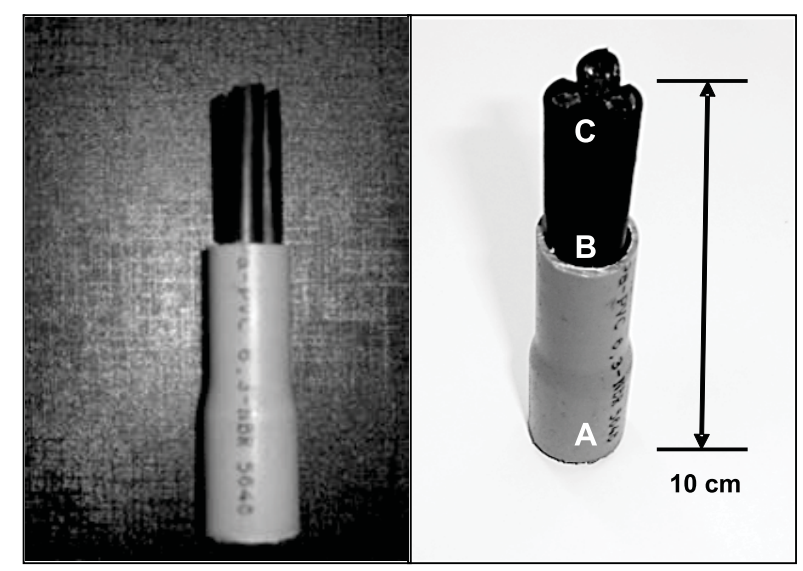

Figura 2 - Sistema desenvolvido para promover incisões na base de miniestacas: A - tubo de PVC como suporte para microtubos; B - microtubos semelhantes aos usados em irrigação, suporte para lâminas de bisturi; e C-lâminas coladas longitudinalmente ao microtubo.

Figure 2 - System designed to promote incisions at minicuttings base. A-PVC pipe as a support for microtubes; $B$-microtubes similar to those used in irrigation, support for scalpel blades; and $C$ - blades glued along the microtube.

Revista Árvore, Viçosa-MG, v.38, n.6, p.1115-1122, 2014 
casa de sombra; e 3) aproveitamento final aos 60 dias na área de rustificação. A metodologia das avaliações foi semelhante às usadas por outros autores (CUNHA et al., 2009; BRODANI et al., 2010a, b; BORGES et al., 2011).

\subsection{Sobrevivência aos 30 dias em casa de vegetação}

Para avaliação de sobrevivência, realizada aos 30 dias, dentro da casa de vegetação, foram quantificados o número de plantas vivas e a taxa de sobrevivência calculada pela equação 1 .

$$
\mathrm{S} \%=(\mathrm{V} / \mathrm{P}) * 100
$$

em que:

$$
\begin{aligned}
& \mathbf{S} \%=\text { porcentagem de sobrevivência; } \\
& \mathbf{V}=\mathrm{n}^{\circ} \text { de plantas vivas; e } \\
& \mathbf{P}=\mathrm{n}^{\circ} \text { de plantas estaqueadas no experimento. }
\end{aligned}
$$

\subsection{Enraizamento aos 45 dias em casa de sombra}

$\mathrm{Na}$ avaliação de enraizamento seguindo a metodologia empregada, computou-se o número de miniestacas enraizadas em relação às miniestacas vivas. Essa é uma abordagem que visa analisar a real habilidade de enraizamento de cada espécie ou clone, de maneira que os dados não sejam influenciados por baixas sobrevivências em casa de vegetação. Esse conceito baseou-se na observação de que alguns fatores que levam a miniestaca à morte não estão ligados à sua habilidade de enraizar. A avaliação de enraizamento foi determinada na casa de sombra aos 45 dias de idade, em porcentagem (equação 2). Determinou-se o número de plantas enraizadas, o qual foi avaliado em função do número de plantas vivas contabilizadas na etapa de sobrevivência. Efetuou-se a avaliação de emissão de raízes de forma visual na extremidade do tubete, sem desagregar o substrato.

$$
\mathrm{E} \%=(\mathrm{e} / \mathrm{S}) * 100
$$

em que:

$\mathbf{E} \%=$ porcentagem de enraizamento;

$\mathbf{e}=\mathrm{n}^{\circ}$ de plantas com raiz aos 45 dias; e

$\mathbf{S}=\mathrm{n}^{\circ}$ de plantas vivas na saída da casa de vegetação.

\subsection{Aproveitamento final aos 60 dias na área de rustificação}

Para avaliação de aproveitamento final de mudas, efetuou-se uma seleção aos 60 dias de idade, quando foram descartadas as mudas mortas ou que não emitiram raiz, deixando uma densidade de $25 \%$ por bandeja (bandeja de 228 células). Essa avaliação foi realizada na fase de rustificação e a taxa de aproveitamento final, determinada pela equação 3 .

$$
\mathrm{AF} \%=(\mathrm{P} / \mathrm{D}) * 100
$$

em que:

$\mathbf{A F} \%=$ porcentagem de aproveitamento final de mudas;

$$
\begin{aligned}
& \mathbf{P}=\mathrm{n}^{\circ} \text { de plantas vivas aos } 60 \text { dias de idade; e } \\
& \mathbf{D}=\mathrm{n}^{\circ} \text { de plantas estaqueadas no experimento. }
\end{aligned}
$$

\subsection{Análise de dados}

Os pressupostos de normalidade dos erros e homogeneidade da variância entre os tratamentos foram verificados pelos testes de Hartley e Lilliefors, respectivamente, fixando-se o nível de probabilidade de erro em $5 \%$. Os dados foram submetidos à análise de variância (ANOVA) a 5\%. As médias foram comparadas pelo teste de Tukey com o mesmo nível de significância.

\section{RESULTADOS}

A análise "boxplot” dos resultados de sobrevivência indica a mediana bastante próxima entre os três tratamentos e apresentam tendência assimétrica negativa (Figura 3). O enraizamento mostra que o tratamento em bisel possui tendência simétrica da caixa em relação à mediana, e a cauda não se sobrepõe aos outros tratamentos. Os tratamentos incisões basais e corte perpendicular (controle) apresentaram assimetria negativa, as caudas sobrepuseram, sugerindo que as médias dos dois tratamentos não diferem entre si. A análise do aproveitamento final apresentou distribuição com maior simetria em relação às medianas e, assim como a avaliação de enraizamento, as médias dos tratamentos incisão basal e corte perpendicular foram superiores e não diferiram entre si. Em nenhuma das três avaliações foram detectados “outliers”. Os dados foram submetidos à transformação angular. 

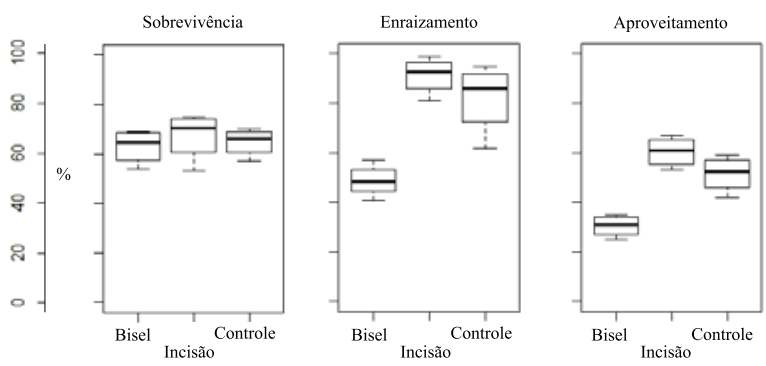

Figura 3 - Análise “boxplot” das avaliações do experimento, comparando porcentagem de cada avaliação nos três tratamentos. Linha escura no centro da caixa indica a mediana, as caixas representam os quartis e as linhas, as caudas.

Figure 3 - Boxplot analyses of the experiment assessment, comparing percentage of each assessment for the three treatments. The bold line in the center indicates the median, the boxes represent the quartiles and the lines represent the tails.

Após a análise explanatória do "boxplot”, a análise de variância mostrou que a porcentagem de sobrevivência verificada aos 30 dias na saída da casa de vegetação indicou que os três tratamentos empregados no experimento não apresentaram diferença significativa, sendo a média de sobrevivência de 65\% (Tabela 1). Em relação à avaliação de enraizamento, o corte perpendicular (testemunha) e com incisão basal diferiram significativamente do corte em bisel, sendo a média de enraizamento verificada de $82 \%$ e $91 \%$, respectivamente. Os resultados de aproveitamento final sugerem que os melhores tratamentos foram os cortes perpendiculares e a incisão basal, 52\% e 61\%, respectivamente.
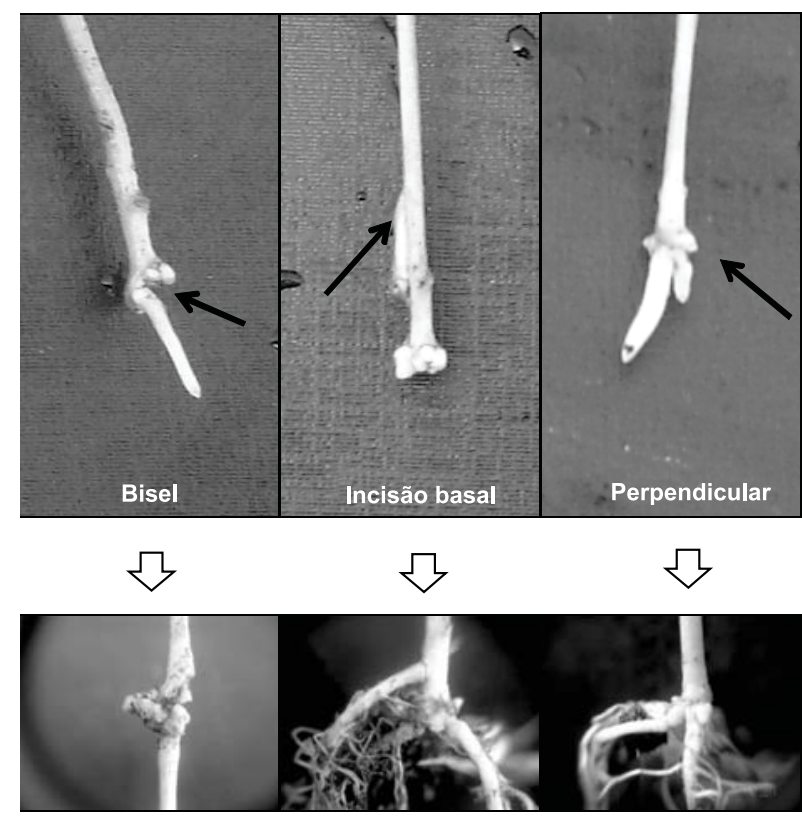

Figura 4-Clone de Eucalyptus urophylla x Eucalyptus globulus subsp. maidenii, com detalhes da base das miniestacas dos três tratamentos, parte superior das fotos registrados aos 30 dias de idade, na casa de vegetação, mostrando os primórdios radiculares e parte inferior das imagens do sistema radicular já formado, aos 45 dias de idade, na casa de sombra.

Figure 4 - Details of the mini-cuttings base of Eucalyptus urophylla $x$ Eucalyptus globulus subsp. maidenii clone, showing the three treatments, upper images registered at 30 days of age in the greenhouse showing the root primordial, and bottom images showing the root system already formed, at 45 days old in the shade house.

Tabela 1 - Porcentagens de sobrevivência, enraizamento e aproveitamento final de miniestacas expressos em porcentagem de um clone híbrido de Eucalyptus urophylla x Eucalyptus globulus subsp. maidenii, sendo: sobrevivências aos 30 dias de idade na saída da casa de vegetação, enraizamento aos 45 dias na casa de sombra e aproveitamento aos 60 dias na rustificação. Teste de Tukey, em que letras diferentes indicam médias significativamente diferentes a $5 \%$ de probabilidade de erro. Símbolo \pm indica limites do intervalo de confiança a $95 \%$.

Table 1 - Survival percentage, rooting and final use of mini-cuttings expressed in percentage of a Eucalyptus urophylla $x$ Eucalyptus globules subsp. maidenii hybrid clone, at 30 days old at the output of the greenhouse, rooting at 45 days in the shade house and final use at 60 days in the hardening area. Tukey test, different letters indicate significantly different means at 5\% error probability. Symbol \pm indicates the limits of the $95 \%$ confidence interval.

\begin{tabular}{lccr}
\hline Tipo de corte & & Porcentagem (\%) & \\
& Sobrevivência & Enraizamento & Aproveitamento \\
\hline Incisão Basal & $67,3 \pm 8,4$ a & $91,3 \pm 6,4$ a & $61,0 \pm 5,5$ a \\
Perpendicular & $64,8 \pm 4,9$ a & $82,3 \pm 12,2$ a & $52,8 \pm 6,5$ a \\
Bisel & $63,0 \pm 5,9$ a & $48,8 \pm 5,6 \mathrm{~b}$ & $30,8 \pm 3,4 \mathrm{~b}$ \\
\hline
\end{tabular}


Mesmo não apresentando diferenças significativas nas avaliações com o corte perpendicular e incisões basais verificou-se maior qualidade visual do sistema radicular para as incisões basais. Pode-se observar, na Figura 4, que as incisões permitem a emissão de raízes também na lateral até a altura de $1 \mathrm{~cm}$, onde foram realizadas as incisões.

\section{DISCUSSÃO}

As porcentagens de sobrevivência são importantes indicadores de manejo adequado no sistema produtivo de mudas clonais, especialmente nas etapas de minijardim clonal e casa de vegetação. Baixas taxas de sobrevivência estão relacionadas a alguns fatores como manejo de água em casa de vegetação, estágio de lignificação das miniestacas, doenças bióticas e, ainda, ligadas aos tratamentos aplicados. A perda de turgidez das miniestacas pode ser decorrente do sistema de manejo, e para ocorrer a divisão celular é necessário que as células do tecido estejam túrgidas. Segundo Goulart e Xavier (2010), a produção de ácido abscísico e de etileno provoca queda precoce de folhas e interfere nos índices de enraizamento.

Neste estudo, obtiveram-se 65\% de sobrevivência, enquanto Oliveira et al. (2012) encontraram 72\% de sobrevivência das miniestacas na saída da casa de vegetação; Borges et al. (2011), 91\% de sobrevivência; e Schwambach et al. (2008), 86\%.

As diferenças nesses índices podem ser função de genótipos, principalmente nesses híbridos, em que uma das espécies parentais (E. globulus) é tida como recalcitrante ao enraizamento, como constatado também por Borges et al. (2011). Rosa et al. (2009) observaram que, embora a sobrevivência das miniestacas na casa de vegetação não garanta sucesso no enraizamento, é fundamental para garantir o processo de propagação vegetativa como um todo. Metodologia de avaliação de enraizamento semelhante foi empregada por Schwambach et al. (2008), em que foi avaliado o número de miniestacas enraizadas em relação ao número de miniestacas vivas.

Segundo Alfenas et al. (2009), a hibridação de Eucalyptus globulus com outras espécies de Eucalyptus, principalmente Eucalyptus urophylla, pode facilitar a propagação vegetativa. Assim como a sobrevivência, em outros estudos o enraizamento apresentou resultados bastante divergentes em relação aos híbridos de $E$. urophylla x E. globulus. Oliveira et al. (2012) encontraram entre $19 \%$ e $68 \%$ de enraizamento na saída da casa de sombra; Borges et al. (2011), entre 58\% e 100\%; e Schwambach et al. (2008), 93\% de enraizamento.

Em estudos sobre o enraizamento de estacas semilenhosas e herbáceas de Syzygium malaccense L., empregando lesões na base e com a aplicação de auxinas exógenas, Bastos et al. (2009); Almeida et al. (2008), de Averrhoa carambola L.; e Trevisan et al. (2008), de Vaccinium sp., não observaram efeito positivo no enraizamento quando foram utilizados esses tratamentos em relação às estacas sem ferimentos na base. Gratieri-Sossella et al. (2008), em propagação de Erythrina crista-galli L., comprovaram que os maiores índices de enraizamento foram obtidos com miniestacas herbáceas, comparadas com estacas lenhosas, semilenhosas e foliares.

O fato de não se terem sido observadas diferenças no enraizamento entre o corte basal perpendicular (testemunha) e a incisão basal pode estar associado ao fato de a característica das miniestacas utilizadas ser material fisiológico herbáceo com baixo grau de lignificação. A hipótese de impedimento físico do lançamento de primórdios radiculares provocados pelos anéis esclerenquimáticos é rejeitada, pois não houve promoção do enraizamento pelos tratamentos sugeridos. Essa hipótese é corroborada por outros autores, a exemplo de Xavier et al. (2009), segundo os quais estacas herbáceas têm maior capacidade de formação de raízes.

Embora o corte basal em bisel tenha proporcionado menor quantidade e qualidade das raízes, isso proporcionou maior área de emissão de raízes na base da estaca, em razão do corte diagonal, com formação de calos, em que foram emitidas as raízes. A formação de calos pode ser um precursor de formação de raízes, porém seu desenvolvimento não é condicionante para a formação de raízes adventícias (FERREIRA et al., 2010).

O resultado do aproveitamento final é composto por vários efeitos. Dentro do ciclo, manter a sobrevivência das miniestacas é um dos principais fatores que influenciam o aproveitamento final, também apontado por Santana et al. (2010). Os resultados deste estudo confirmam que a sobrevivência influencia o aproveitamento final, mesmo com altos índices de enraizamento. 
Observações indicaram que as incisões mudaram o aspecto morfológico da disposição das raízes na base das miniestacas. Isso pode ser importante ponto de partida no desenvolvimento de novas abordagens e tecnologias no desenvolvimento da clonagem por miniestaquia em genótipos recalcitrantes, como Eucalyptus globulus, Eucalyptus nitens, Eucalyptus cloeziana, Eucalyptus dunnii e Eucalyptus benthamii e espécies do gênero Corymbia. Os resultados deste estudo evidenciaram a importância da continuidade de pesquisas sobre a influência das incisões basais na qualidade e velocidade da formação do sistema radicular.

\section{CONCLUSÕES}

A propagação vegetativa do clone híbrido de Eucalyptus urophylla x Eucalyptus globulus é viável por miniestaquia, com altos índices de enraizamento, independentemente do sistema de corte basal.

A introdução de métodos de corte basal alternativos das miniestacas em bisel e de incisões longitudinais não estimulou a formação de raízes, em comparação com o corte basal perpendicular (testemunha).

\section{AGRADECIMENTOS}

À empresa CMPC Celulose Riograndense, pela disponibilização da estrutura do viveiro, incluindo o apoio da equipe técnica, e pela concessão de bolsa.

\section{REFERÊNCIAS}

ALFENAS, A. C.; ZAUZA, E. A. V.; MAFIA, R. G.; ASSIS, T. F. Clonagem e doenças de eucalipto. 2 ed. Viçosa, MG: Universidade Federal de Viçosa, 2009. 500 p.

ALMEIDA, E.J.; SCALOPPI, E.M.T.; JESUS, N.; MARTINS, A.B.G. Propagação de jambeiro vermelho (Syzygiummalaccensel.) por estaquia de ramos herbáceos. Bioscience Journal, v.24, n.1, p.39-45, 2008.

ASSIS, T. F.; MAFIA, R. G. Hibridação e clonagem. In: BORÉM, A. (Ed.). Biotecnologia florestal,Viçosa, MG: Suprema, 2007, p.93-121.

BASTOS, D. C.; SCARPARE FILHO, J.

A.;LIBARDI, M. N.; PIO, R. Estiolamento, incisão na base da estaca e uso do ácido indolbutírico na propagação da caramboleira por estacas
lenhosas.Ciências Agrotécnicas, v. 33, n. 1, p. 313-318, 2009.

BORGES, S.R.; XAVIER,A.; OLIVEIRA, L.S.; MELO,L.A.; ROSADO, M.A. Enraizamento de miniestacas de clones híbridos de Eucalyptus globulus. Revista Árvore, v.35, n.3, p.425-434. 2011.

BRONDANI, G. E.; WENDLING, I.; GROSSI, F.G.; DUTRA, L.; ARAÚJO, M. A. Miniestaquia de Eucalyptus benthamii x Eucalyptus dunnii: (ii) sobrevivência e enraizamento de miniestacas em função das coletas e estações do ano. Ciência Florestal, v.20, n.3, p. 453-465, 2010a.

BRONDANI, G.; GROSSI, F.; WENDLING, I.; DUTRA, L.; ARAUJO, M. A. Aplicação de IBA para o enraizamento de miniestacas de Eucalyptus benthamii maiden \& Cambage x Eucalyptus dunnii maiden. Acta Scientiarum. Agronomy, v.32, n.4, p.667-674. 2010b.

CAMOLESI, M. R.; UNEMOTO, L. K. P.; SACHS,J. D.; ROBERTO, S. R.; SATO, A. J.; FARIA, A. P.;RODRIGUES, E. B.; SILVA, J. V. Enraizamentode estacas semilenhosas de pessegueiro "Okinawa” sob efeito de lesão e ácido indolbutírico. Ciência Rural, v.37, n.6, p. 1805-1808, 2007.

CUNHA, A.C.M.C.M.; PAIVA, H.N.; LEITE, H.G.; BARROS, N.F.; LEITE, F.P. Influência do estado nutricional de minicepas no enraizamento de miniestacas de eucalipto. Revista Árvore, v.33, n.4, p.607-615, 2009.

FACHINELLO, J.C.; HOFFMANN, A.; NACHTIGAL, J.C. Propagação de plantas frutíferas. Brasília: Embrapa Informação Tecnológica, 2005. 221p.

FACHINELLO, J. C.; HOFFMANN, A.; NACHTIGAL, J. C.; KERSTEN, E.; FORTES, G. R. L. Propagação de plantas frutíferas de clima temperado. Pelotas: Universidade Federal de Pelotas, 1995. 179 p.

FERREIRA, B. G. A.; ZUFFELLATO-RIBAS, K. C.; WENDLING, I.; KOEHLER, H. S.; NOGUEIRA, A. C. Miniestaquia de Sapium glandulatum (Vell.) Pax. com o uso de ácido indolbutírico e ácido naftaleno acético. Ciência Florestal, v.20, n.1, p.19-31, 2010.

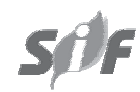

Revista Árvore, Viçosa-MG, v.38, n.6, p.1115-1122, 2014 
GOULART, P. B.; XAVIER, A. Influência do modo de acondicionamento de miniestacas no enraizamento de clones de Eucalyptus grandis $\mathrm{x}$ E. urophylla. Revista Árvore, v.34, n.3, p.407415, 2010.

GRATIERI-SOSSELLA, A.; PETRY, C.; NIENOW, A. A. Propagação da corticeira do banhado (Erythrina crista-galli L.) (Fabaceae) pelo processo de estaquia. Revista Árvore, v.32, n.1, p.163-171, 2008.

HARTMANN, H. T.; KESTER, D. E.; DAVIES JUNIOR, F. T.; GENEVE, R. L. Plant propagation: principles and practices. 7.ed. New Jersey: Prentice-Hall, 2002. 880 p.

OLIVEIRA, L. S.; XAVIER, A.; DIAS, P. C.; CORREIA, A. C. G.; BORGES, S. R.; TAKAHASHI, E. K. ; PAIVA, H. N. Enraizamento de miniestacas e microestacas de clones de Eucalyptus urophylla $\times$ E. globulus e de Eucalyptus grandis $x$ E. globulus. Scientia Forestalis, v.40, n.46, p.507-516, 2012.

ROSA, L. S.; WENDLING, I.; GROSSI, F.;

REISSMANN, C. B. Efeito da dose de nitrogênio e de formulações de substratos na miniestaquia de Eucalyptus dunnii maiden. Revista Árvore, v.33, n.6, p.1025-1035, 2009.
SANTANA, R. C.; DUTRA, T. R.; CARVALHO NETO, J. P.; NOGUEIRA, G. S.; GRAZZIOTTI, P. H.; BARROS FILHO, N. F. Influence of leaf area reduction on clonal production of eucalyptus seedlings. Cerne, v. 16, p. 251-257, 2010.

SCHWAMBACH, J.; RUEDELL, C. M.; ALMEIDA, M. R.; PENCHEL, R. M.; ARAÚJO, E. F.; FETT-NETO, A. Adventitious rooting of Eucalyptus globulus x maidennii minicuttings derived from mini-stumps grown in sand bed and intermittent flooding trays: a comparative study. New Forests, v. 36, n. 3, p. 261-271, 2008.

TREVISAN, R.; FRANZON, R.C.; FRITSCHE NETO, R.; GONÇALVES, R.S.; GONÇALVES, E.D.; ANTUNES, L.E.C. Enraizamento de estacas herbáceas de mirtilo: influência da lesão na base e do ácido indolbutírico. Ciências Agrotecnica, v.32, n.2, p.402-406, 2008.

XAVIER, A.; COMÉRIO, J. Microestaquia: uma maximização da micropropagação de Eucalyptus. Revista Árvore, v.20, n.1, p.9-16, 1996.

XAVIER, A.; WENDLING, I.; SILVA, R. L. Silvicultura clonal: princípios e técnicas. Viçosa, MG: Universidade Federal de Viçosa, 2009. 272p. 